\title{
Reconciling economic viability and socio-ecological aspirations in London urban microfarms
}

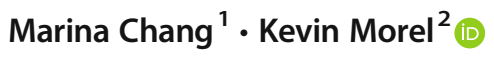 \\ Accepted: 15 January 2018 / Published online: 1 February 2018 \\ (C) INRA and Springer-Verlag France SAS, part of Springer Nature 2018
}

\begin{abstract}
Few scholars have investigated the economic viability of urban farms in industrialized countries. This study focused on urban community microfarms - small-scale organic market gardens committed to social work activities — in London. Our objective was to investigate the extent to which economic viability was (i) possible for urban microfarms in London and (ii) compatible with the other social and ecological aspirations of microfarmers. The simulation model MERLIN was adapted to London, based on 10 case studies. We analyzed the likelihood of viability - that is, the percentage of economically viable simulations (out of 1000 simulations) - of 192 different strategic scenarios of microfarms. Based on the modeling outputs, a collective workshop was organized with 11 urban farmers to discuss the possibility of reconciling socio-ecological aspirations and economic viability in an urban context. This is the first time that modeling and discussions with stakeholders are combined to explore the viability of urban agriculture. Our novel study shows that urban microfarms can be viable and that viability can be increased by focusing on short-cycle and high added-value leaf vegetables grown in high tunnels and sold at high prices to restaurants. Such strategies can lead urban farmers to make trade-offs with their socio-ecological aspirations. Costs can be decreased by taking advantage of community resources such as volunteer labor or agreements with local councils to rent land at a low rate. Social work (training, hosting community events) is a key condition to access these resources but entails more complex farm management.
\end{abstract}

Keywords Agroecology $\cdot$ Sustainability $\cdot$ Urban agriculture $\cdot$ Organic farming $\cdot$ Trade-offs

\section{Introduction}

\subsection{The challenge of economic viability for urban microfarms}

The positive social and ecological impacts that urban agriculture can have on cities are increasingly recognized: health and well-being, urban resilience, climate mitigation, water management, recycling organic waste, reconnecting urban people to nature, green jobs creation, and biodiversity restoration (Lovell 2010; Pearson et al. 2010; Connors and McDonald 2011; Ackerman et al. 2014; Biel 2014; Barthel et al. 2015). In addition to social and ecological functions, the degree to

Kevin Morel

kevin.morel@posteo.net

1 Centre for Agroecology, Water and Resilience (CAWR), Coventry University, Priory Street, Coventry CV1 5FB, UK

2 UMR SADAPT, INRA, AgroParisTech, Université Paris-Saclay, 16, rue Claude Bernard, 75231 Paris Cedex 5, France which urban agriculture will receive political and cultural support depends on perceptions of whether it can have a significant impact on local food availability or not (Ackerman et al. 2014). Based on various methods of mapping vacant and green land, and on productivity hypotheses, a growing number of studies have estimated that the potential contribution of urban agriculture to supplying cities with vegetables in industrialized countries could be significant (among others, Colasanti and Hamm 2010; McClintock et al. 2013; Ackerman et al. 2014). For example, in London, Garnett (2000) calculated that the peri-urban greenbelt of 53,600 ha could supply up to $12 \%$ of the inhabitants' vegetable intake, and urban agriculture inside the city (including private gardens), $6 \%$. Beyond the demonstration of urban agriculture's various functions and potentialities, very few studies have been carried out to assess the economic viability of urban farms (Kaufman and Bailkey 2000), which is a central issue if these farms are to play a growing role in food systems.

Exploring the economic viability of urban farms is particularly relevant in London, where various local programs have fostered the development of sustainable food production 
systems over the past decade (LDA 2006). While acknowledging diverse forms of urban agriculture in London such as community gardens, home gardens, allotments, guerrilla gardening, rooftop gardens, greenhouses, aquaponics, and city farms, our research has focused essentially on urban community microfarms - although this is not a familiar term in London. Inspired by the work of Daniel (2017) and Morel and Léger (2016), urban community microfarms (hereafter called microfarms) are defined as small-scale, organic, soilbased market gardens, often committed to social work activities. In line with their wish to change food systems while reconnecting farmers to consumers, based on fair prices for both, they sell their production locally through short supply chains. Microfarmers not only argue that growing food in soil consumes less energy and is more "authentic" than in aquaponics or rooftop systems, they also consider that cultivating the land is a political act to claim the right for citizens to take greater control of the urban space (CFGN 2016, Just Space 2016). Given the difficulty of accessing land in London, a partnership with landowners, either private or public or both, is essential to their existence. Most microfarms rely on some subsidies in exchange for the multiple benefits they bring to local communities through social work activities, e.g., training, teaching, hosting community events, etc. The starting point of this research was the fact that a growing number of existing and aspiring urban microfarmers wonder whether it is possible to make a living from food production in London (Sustain 2016).

\subsection{Exploratory participatory research}

Our objective was to investigate the extent to which economic viability was (i) possible for urban microfarms in London and (ii) compatible with microfarmers' other social and ecological aspirations. When we started the research in spring 2016, very few data were available on the production, incomes, and labor of microfarms (Sustain 2016). As researchers, we wanted to carry out a participatory study (including data collection) because we were convinced by the abundant scientific literature showing that involving stakeholders in farm-based research is a powerful tool to identify constraints and solutions related to decision making, to enhance collective learning, and to improve the legitimacy of research (Pretty 1995; Bezner Kerr et al. 2007; Voinov and Bousquet 2010). Although urban microfarmers showed keen interest in our work, they were reluctant to be involved in a participatory research process that they perceived as too time-consuming. We managed to convince 11 of them to be part of a 3-month exploratory study designed to limit the time that their involvement would require and to give them the opportunity to assess whether a more ambitious participatory study in the future might interest them.

We chose to use the MERLIN model to simulate economic viability assuming that computational modeling could facilitate the systematic investigation of widely diverse microfarm scenarios, beyond the limited number of possible case studies and underpinned by a logic of in silico experimentation (Martin et al. 2011). MERLIN is a stochastic model developed on extensive farm data collection (Morel 2016; Morel et al. 2018). It simulates the production, income, annual workload, and utilized agricultural area (UAA) of microfarms for diverse strategic scenarios (detailed later) and has been used to investigate the economic viability of French rural microfarms (Morel et al. 2017). Relying on the qualitative analysis of semi-structured interviews with urban farmers, we adapted MERLIN to the London urban context and analyzed the economic viability of 192 different strategic scenarios of microfarms. As in most cases, profit is not an urban farmer's main objective; the economic viability of their initiatives has to be considered within a wider framework integrating their socio-ecological aspirations (Morel and Léger 2016). We thus used the quantitative modeling outputs as the basis of a collective workshop organized with urban farmers to discuss the possibility of reconciling socio-ecological aspirations and economic viability in an urban context.

In participatory research, the form and level of stakeholders' involvement can vary. In our study, they were not involved in creating the model or designing the research process, unlike more ambitious participatory approaches (Pretty 1995; Bezner Kerr et al. 2007; Voinov and Bousquet 2010). However, they were engaged in sharing their experiences in urban farming to adapt the MERLIN model. They were also involved in validating model outputs. This rather light form of participatory modeling through consultation (Pretty 1995) was adapted to our exploratory research aimed at limiting microfarmers' time investment. Based on this study, we discussed perspectives for further research to support urban farmers (Fig. 1).

\section{Material and methods}

\subsection{Selecting case-studies and analyzing interviews}

When the research started in spring 2016, we called over 20 urban farmers who had been identified through the existing network of one of the co-authors who had previously worked with urban farmers in London. We quickly realized that at that stage, the farmers were not willing to invest a lot of time in the research, despite keen interest in the subject. As mentioned in the "Introduction," we therefore chose to limit their involvement in an exploratory study. From the 20 initial farms, we selected 10 farms through a theoretical sampling approach (Eisenhardt 1989) to cover the diversity of microfarms in terms of location, farming practices, and marketing channels (Table 1). Only 6 of those 10 farms agreed to get involved in the research, and we completed the sample with four existing 
Fig. 1 Two urban microfarms in Outer London (left picture) and Inner London (right picture). Urban farms can have positive ecological and social impacts on cities, but their economic viability is threatened by high costs of labor and land in urban areas, especially in London

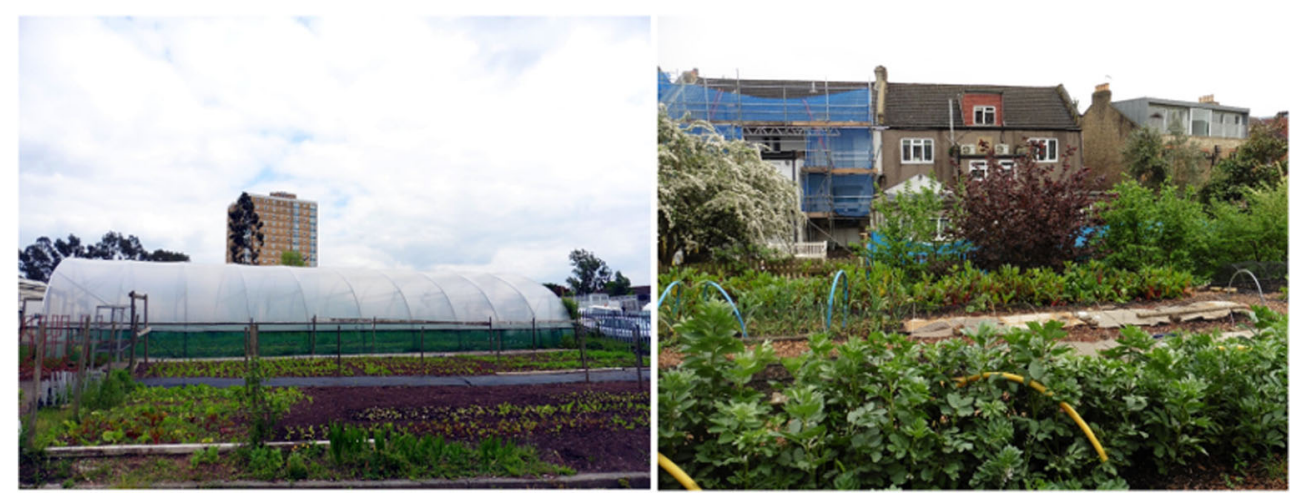

case studies reported by a British non-profit organization supporting urban farms (Sustain 2012, 2016). Three case studies were located in Inner London and seven in Outer London where the access to land was relatively simpler in terms of available space and rent costs. Inner London is the name of the London boroughs which form the interior part of London $\left(319 \mathrm{~km}^{2}\right)$ where the density of population is more than double that of Outer London $\left(1253 \mathrm{~km}^{2}\right)$ which corresponds to other London boroughs forming a ring around Inner London.

On each farm, we interviewed the farmer who showed the most interest in the research. Each semi-structured interview was carried out on the farm, lasted from 2 to $3 \mathrm{~h}$, and involved a site visit. To structure the interviews, we used the conceptual framework that Morel and Léger (2016) developed to study microfarms in France, rather than a precise list of questions. The framework helped the interviewer to remember all the topics to be addressed yet allowed him/her the flexibility to adapt to each situation and to move naturally from one topic to the next. This ensured that the interviews were spontaneous and fluid (Olivier de Sardan 2008). The main topics addressed were investment, marketing strategy, farming practices, community integration, and farmers' aspirations and objectives. Notes were taken manually. The information thus collected was processed by means of inductive qualitative analysis, which is a classic approach in grounded research (Glaser and Strauss 2009), using thematic coding and matrix tools described by Miles and Huberman (1984). More and more abstract categories were built on the basis of an iterative cross-analysis of interview content and allowed us to determine the most relevant variables and options to be explored in the simulations.

\subsection{Adapting the MERLIN model to London}

The MERLIN model involves (i) mixed models to predict yields and production workload per crop for different crops, according to farming practices, (ii) a crop planning module, and (iii) a module calculating economic indicators (gross sales, added value, incomes) and utilized agricultural area (UAA) for a given level of annual workload based on costs,

Table 1 London urban microfarms involved in the case studies

\begin{tabular}{|c|c|c|c|c|c|c|c|}
\hline Farm & $\begin{array}{l}\text { Utilized agricultural } \\
\text { area, } U A A\left(\mathrm{~m}^{2}\right)\end{array}$ & $\begin{array}{l}\text { Cultivated } \\
\text { acreage }\left(\mathrm{m}^{2}\right)\end{array}$ & $\begin{array}{l}\text { Ratio of cultivated } \\
\text { acreage in } U A A\end{array}$ & $\begin{array}{l}\text { Ratio of tunnels in } \\
\text { cultivated acreage }\end{array}$ & Location & $\begin{array}{l}\text { Major marketing } \\
\text { channels }\end{array}$ & $\begin{array}{l}\text { Social } \\
\text { work }\end{array}$ \\
\hline $\mathrm{A}$ & 1012 & 500 & $49 \%$ & $4 \%$ & $I$ & $R$ & $C, T$ \\
\hline $\mathrm{B}$ & 24,276 & 16,200 & $67 \%$ & $12 \%$ & $O$ & $B$ & $T$ \\
\hline $\mathrm{C}$ & 6069 & 500 & $8 \%$ & $14 \%$ & $O$ & $R$ & $T$ \\
\hline $\mathrm{D}$ & 7190 & 4046 & $56 \%$ & $40 \%$ & $O$ & $B, R$ & $C, T$ \\
\hline $\mathrm{E}$ & 4500 & 1500 & $33 \%$ & $17 \%$ & $O$ & $B, R$ & $T$ \\
\hline $\mathrm{F}$ & 48,552 & 18,207 & $38 \%$ & $11 \%$ & $O$ & $B, M, R$ & $C, T$ \\
\hline $\mathrm{G}$ & 28,322 & 14,000 & $49 \%$ & $4 \%$ & $O$ & $B$ & $C, T$ \\
\hline $\mathrm{H}$ & 200 & 150 & $75 \%$ & $0 \%$ & $I$ & $R$ & $C$ \\
\hline I & 6000 & 4046 & $67 \%$ & $25 \%$ & $I$ & $B$ & $C, T$ \\
\hline $\mathrm{J}$ & 2000 & 1000 & $50 \%$ & $35 \%$ & $O$ & $B, M, R$ & $C, T$ \\
\hline
\end{tabular}

Utilized agricultural area includes the area dedicated to buildings, footpaths, and gathering spaces, whereas cultivated acreage refers only to the area dedicated to growing (not including footpaths and other spaces). Throughout the paper, "tunnels" refer to unheated high tunnels

Location: $I$ Inner London, $O$ Outer London. Marketing channels: $R$ restaurants or cafes, $B$ vegetable boxes, $M$ open air markets or local stores. Social work: $C$ hosting community events, $T$ training and teaching 
prices, and land use parameters (Morel 2016; Morel et al. 2018). For a given scenario of farming practices and marketing strategy, MERLIN can perform various simulations that take into account the variability of yields, production workload per crop, and cropping plans observed in the field. To do so, the parameters impacting yields and production workload per crop are drawn randomly in a normal distribution for each simulation. Similarly, the crop-planning module designs random cropping plans based on vegetable cropping cycles (month of planting and harvesting for different crops) from a large database of possibilities (Chang and Morel 2017). The model ensures that the respective acreages of the different cropping cycles allow to match specific requirements such as rotation criteria or diversified offer. The integration of random effects allows one to explore a wide range of possibilities through simulations, based on the variability and constraints observed in the field (Morel 2016; Morel et al. 2018). This method is specifically relevant in London where existing case studies are limited and therefore preclude statistical analysis on real data.

To simulate microfarm scenarios in London, we adapted the MERLIN model (Tables 2 and 3) based on discussions with urban farmers during the interviews, on quantitative data provided by urban farmers where possible (prices, costs), and on grey literature (Sustain 2012, 2016). These sources indicate that the objective of London microfarmers was to optimize land use, given the small acreages available. To meet this objective, the farmers opted for high planting densities allowed by manual labor. The impacts of this approach on yields and workload were modeled using the parameters of the original MERLIN module designed for French microfarmers with the same strategy. London farmers also grew several crops in rapid succession over the year (from two to four crops per plot per year), using unheated high tunnels and low tunnels to shorten cropping cycles and produce throughout the winter. In the original MERLIN model, the possible vegetable cycles designed by the crop-planning module are characterized both in high tunnels and outdoors (Chang and Morel 2017). The share of high tunnels in the cultivated acreage therefore impacts the crop planning possibilities. The "outdoor" cropping possibilities account for the fact that French microfarmers, like urban microfarmers, could use low tunnels. However, both French and London microfarmers make moderate use of low tunnels, which have a relatively minor impact on cropping cycle and growing season length. High tunnels, on the other hand, can have a much greater impact on these production factors and, consequently, viability. This is the reason why the MERLIN model considers only high tunnels, the ratio of which in cultivated acreage is a variable in the simulated scenarios. Throughout the rest of this paper, they will be referred to simply as "tunnels." Social activities were not considered in the MERLIN model, which focuses only on vegetable production. The articulation of social work and farming activities was one of the subjects of discussion with practitioners.

\subsection{Assessing the viability of different scenarios}

Based on the comparative analysis of the 10 case studies, we defined six variables representing the main strategies and constraints that impacted farms' viability. For each variable, we considered contrasting options which reflected the diversity encountered among London microfarms (Table 4).

The crops grown for each marketing offer are presented in Table 3 with their respective prices for each pricing strategy and their botanical family considered for rotation criteria. A scenario was defined by the articulation of the six variables. The combination of the different options for the six variables (respectively 2, 4, 2, 3, 2, 2 options) led to 192 different scenarios. For each scenario, we ran 1000 simulations that varied with respect to cropping plans, yields, and production workload per crop. Mean values and variability of yields and workload per crop are presented in Table 3.

In the sample of London farms, production costs accounted for 20 to $30 \%$ of sales and were drawn randomly within this range for each simulation. These costs excluded equipment depreciation and bank loans to pay, as most London farms relied on donations and crowd funding for initial investment (tunnels, tools). They also excluded the costs of labor and land

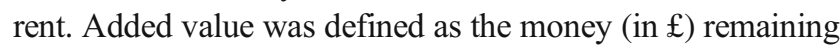
from sales once production costs had been paid (distinct from lay terms such as "margin" or "profit," whose definition varies among economic sectors and countries and can integrate costs of rent).

For each simulation, MERLIN calculated the added value per unit area of utilized agricultural area and per unit labor.

The analysis of the case studies highlighted the fact that the main costs of urban microfarms were labor remuneration and land rent. The economic viability of a simulation was assessed as the possibility for the added value to cover these two costs, represented by Eq. 1, assuming that all labor was paid (no volunteer work):

\section{Land rent cost $\times$ Utilized agricultural area}

$$
+ \text { Labor cost } \times \text { Workload } \leq \text { Added value }
$$

Dividing Eq. 1 by added value (always positive) led to Eq. 2 defining economic viability as follows:

$\frac{\text { Land rent cost }}{\text { Added value per unit area }}+\frac{\text { Labor cost }}{\text { Added value per unit labor }} \leq 1$

where $\frac{\text { Land rent cost }}{\text { Added value per unit area }}+\frac{\text { Labor cost }}{\text { Added value per unit labor }}$ was called "viability ratio."

For each scenario, we called "likelihood of viability" the percentage of simulations (out of 1000) with a viability ratio 
Table 2 Adaptations of the MERLIN model to simulate London microfarms

\begin{tabular}{|c|c|c|}
\hline $\begin{array}{l}\text { Module of } \\
\text { MERLIN }\end{array}$ & Parameters chosen and changes & Justification \\
\hline \multirow[t]{2}{*}{$\begin{array}{l}\text { Prediction of } \\
\text { yields and } \\
\text { workload }\end{array}$} & $\begin{array}{l}\text { To simulate yields and production workload for the different } \\
\text { crops, we used parameters from the original MERLIN model, } \\
\text { considering the following strategies: (i) high planting density } \\
\text { allowed by manual labor and occasional motorization for } \\
\text { superficial tillage, (ii) low input practices such as straw } \\
\text { mulching, growing green manures, composting local organic } \\
\text { matter and preparing farm-made plant decoctions to replace } \\
\text { commercial organic fertilizers and phytosanitary products, and } \\
\text { (iii) building of own farm equipment* in the setting-up phase to } \\
\text { reduce investment costs (Morel et al. 2017). The resulting } \\
\text { yields and production workload per crop are presented in } \\
\text { Table 3. }\end{array}$ & $\begin{array}{l}\text { The strategies considered were the most common in the London } \\
\text { case studies. }\end{array}$ \\
\hline & $\begin{array}{l}\text { A } 70 \% \text { reduction coefficient was allocated to the yields predicted } \\
\text { by the original MERLIN model for the crops grown outdoors. }\end{array}$ & $\begin{array}{l}\text { The very few data we were able to find on the studied microfarms' } \\
\text { yields suggested that the London climatic context could be less } \\
\text { favorable than in Northern France where the MERLIN model } \\
\text { was built. We allocated a reduction coefficient in order not to } \\
\text { overestimate yields. The level of } 70 \% \text { was chosen to match the } \\
\text { few sparse data we were able to obtain in London. For crops } \\
\text { grown in tunnels, yields did not seem to be different from } \\
\text { Northern France. }\end{array}$ \\
\hline \multirow[t]{3}{*}{ Crop planning } & $\begin{array}{l}\text { From the original } 50 \text { types of crop simulated by MERLIN, only } \\
36 \text { were used in the London context (Table } 3 \text { ). }\end{array}$ & $\begin{array}{l}\text { Urban farmers from our study did not grow winter storage crops } \\
\text { (such as potatoes or carrots) because these crops stay in the soil } \\
\text { for too long and therefore have a low added value, which } \\
\text { makes them unfeasible in a context where acreage is limited } \\
\text { and expensive. }\end{array}$ \\
\hline & $\begin{array}{l}\text { Among the different climatic contexts parameterized in the } \\
\text { original MERLIN model, we considered only the "cool } \\
\text { climate," corresponding to the Normandy climate, with } 274 \\
\text { cropping possibilities for } 36 \text { crops (Online Resource 1). }\end{array}$ & $\begin{array}{l}\text { Based on a sample of crops, we ensured with urban farmers that } \\
\text { the Normandy climate was close enough to the London one in } \\
\text { terms of cropping cycle possibilities. For example, in both } \\
\text { climates, tomatoes could be harvested from July to } \\
\text { October/November in unheated high tunnels. }\end{array}$ \\
\hline & $\begin{array}{l}\text { The original MERLIN module simulated cropping plans to } \\
\text { provide a diversity of crops throughout the year, to be sold in } \\
\text { vegetables boxes. In this study, the module was adapted to } \\
\text { generate cropping plans maximizing land use throughout the } \\
\text { year, which met rotation criteria (Table 4). Rotations were } \\
\text { based on a minimal return time (in years) of botanic families } \\
\text { (Table 3). }\end{array}$ & $\begin{array}{l}\text { Unlike French rural microfarmers, the main priority for London } \\
\text { farmers was to maximize land use and not plant diverse } \\
\text { varieties of crops because of the limited space. Moreover, in } \\
\text { London, the demand for local fresh vegetables was so high that } \\
\text { it was easy for microfarmers to retail sell their crops, even with } \\
\text { a limited diversity. }\end{array}$ \\
\hline $\begin{array}{l}\text { Calculation of } \\
\text { economic } \\
\text { indicators }\end{array}$ & \multicolumn{2}{|l|}{ See the section headed "Assessing the viability of different scenarios." } \\
\hline $\begin{array}{l}\text { Calculation of } \\
\text { utilized } \\
\text { agricultural } \\
\text { area }\end{array}$ & $\begin{array}{l}\text { We considered in MERLIN that the cultivated acreage dedicated } \\
\text { to crop production accounted for } 50 \% \text { of the utilized } \\
\text { agricultural area (the rest being potentially occupied by } \\
\text { buildings, footpaths, wildlife areas and gathering space). }\end{array}$ & $\begin{array}{l}\text { This value was the average among the } 10 \text { microfarms studied } \\
\text { (Table 1). }\end{array}$ \\
\hline
\end{tabular}

*Farmers construct as many tools, types of equipment, and farm buildings as possible, from previously used or free materials (do-it-yourself approach)

less than or equal to 1 . For all viable simulations, the utilized agricultural area was calculated for an annual workload of $1800 \mathrm{~h}$, which corresponded to a full-time job for a single market gardener.

\subsection{A collective workshop to validate and discuss the model with microfarmers}

A 3-h collective workshop was organized and facilitated in London by the two authors of the paper with eight microfarmers within the selected 10 case studies, along with another three practitioners from other microfarms in London, to validate and discuss the modeling outputs. The workshop was audio-recorded and analyzed using the same qualitative methods, as for interviews (see above).

As no data were available about added value and workload on London microfarms, the model validation relied entirely on the expertise of these practitioners. We considered that validation by stakeholders was sufficient for this purpose (Troitzsch 2004). Practitioners' reactions to the model were analyzed 
Table 3 Characteristics of the crops considered in the simulations

\begin{tabular}{|c|c|c|c|c|c|c|c|}
\hline Crop & Botanical family & $\begin{array}{l}\text { Low price } \\
\left(£ \mathrm{~kg}^{-1}\right)\end{array}$ & $\begin{array}{l}\text { High price } \\
\left(£ \mathrm{~kg}^{-1}\right)\end{array}$ & $\begin{array}{l}\text { Mean yield* } \\
\left(\mathrm{kg} \mathrm{m}^{-2}\right)\end{array}$ & $\begin{array}{l}\text { Mean production } \\
\text { workload** } \\
\left(\min \mathrm{m}^{-2}\right)\end{array}$ & $\begin{array}{l}\text { Grown } \\
\text { outdoors }\end{array}$ & $\begin{array}{l}\text { Grown in } \\
\text { tunnel }\end{array}$ \\
\hline Broad bean & Fabaceae & 5 & 6 & $2.1 \pm 0.3$ & $24.2 \pm 5.4$ & • & • \\
\hline Broccoli & Brassicaceae & 2.5 & 4 & $0.8 \pm 0.1$ & $16.6 \pm 3.8$ & • & \\
\hline Brussels sprouts & Brassicaceae & 5 & 7 & $1.1 \pm 0.2$ & $27.0 \pm 6.2$ & • & \\
\hline Cabbage & Brassicaceae & 2.5 & 4 & $3.7 \pm 0.6$ & $21.3 \pm 4.7$ & • & • \\
\hline Cauliflower & Brassicaceae & 3 & 4 & $1.0 \pm 0.2$ & $18.2 \pm 3.8$ & • & \\
\hline Celery & Apiaceae & 3 & 5 & $2.6 \pm 0.4$ & $19.7 \pm 4.5$ & • & • \\
\hline Chard (G) & Chenopodiaceae & 4 & 7.5 & $2.3 \pm 0.3$ & $19.8 \pm 4.6$ & • & • \\
\hline Chicoree (G) & Asteraceae & 10 & 14 & $1.5 \pm 0.2$ & $13.5 \pm 3.1$ & • & • \\
\hline Chilli & Solanaceae & 10 & 14 & $0.3 \pm 0$ & $24.9 \pm 5.6$ & & - \\
\hline Chinese cabbage $(\mathrm{G})$ & Brassicaceae & 4 & 7.5 & $3 \pm 0.4$ & $23.3 \pm 5.5$ & • & • \\
\hline Claytonia (G) & Portulacaceae & 10 & 14 & $0.9 \pm 0.1$ & $37.4 \pm 8.6$ & - & • \\
\hline Cucumber & Cucurbitaceae & 3 & 4.5 & $7.0 \pm 1.1$ & $94.5 \pm 22$ & & • \\
\hline Eggplant & Solanaceae & 5 & 7 & $4.1 \pm 0.6$ & $41.1 \pm 9.7$ & & • \\
\hline Fennel & Apiaceae & 3 & 4 & $1.7 \pm 0.3$ & $22.1 \pm 5.1$ & • & • \\
\hline French bean & Fabaceae & 5 & 7.5 & $1.7 \pm 0.3$ & $27.9 \pm 6.4$ & $\bullet$ & $\bullet$ \\
\hline Herbs* & Miscellaneous & 20 & 45 & $1.5 \pm 0.2$ & $23.6 \pm 5.5$ & • & • \\
\hline Kale* & Brassicaceae & 7 & 10 & $1.0 \pm 0.1$ & $23.1 \pm 5.3$ & • & $\bullet$ \\
\hline Kohlrabi & Brassicaceae & 3 & 5 & $3.6 \pm 0.5$ & $21.4 \pm 4.9$ & $\bullet$ & $\bullet$ \\
\hline Leek & Alliaceae & 3 & 5 & $2.3 \pm 0.4$ & $37.8 \pm 8.6$ & $\bullet$ & $\bullet$ \\
\hline Lettuce (G) & Asteraceae & 10 & 14 & $2.4 \pm 0.4$ & $18.3 \pm 4.2$ & • & - \\
\hline Melon & Cucurbitaceae & 6 & 7 & $3.7 \pm 0.6$ & $24.8 \pm 5.8$ & & • \\
\hline Mixed leaves $1(\mathrm{G})$ & Brassicaceae & 10 & 14 & $0.9 \pm 0.1$ & $31.6 \pm 7.3$ & • & • \\
\hline Mixed leaves $2(\mathrm{G})$ & Miscellaneous & 10 & 14 & $0.9 \pm 0.1$ & $31.5 \pm 7.3$ & • & • \\
\hline Pea & Fabaceae & 3 & 5 & $1.1 \pm 0.2$ & $31.4 \pm 7.2$ & • & • \\
\hline Radish & Brassicaceae & 4 & 5 & $1.6 \pm 0.2$ & $21.3 \pm 4.9$ & • & $\bullet$ \\
\hline Spinach $(G)$ & Chenopodiaceae & 7 & 10 & $1.0 \pm 0.1$ & $29.8 \pm 6.8$ & - & • \\
\hline Spring onion & Alliaceae & 2 & 4 & $3.3 \pm 0.5$ & $19.2 \pm 4.5$ & • & $\bullet$ \\
\hline Squash & Cucurbitaceae & 2.5 & 3.5 & $1.4 \pm 0.2$ & $32.1 \pm 7.5$ & - & • \\
\hline Strawberry & Rosaceae & 16.25 & 20 & $3.4 \pm 0.5$ & $33.6 \pm 7.8$ & • & - \\
\hline Sweet pepper & Solanaceae & 7 & 9 & $6.3 \pm 0.9$ & $97.7 \pm 22.9$ & & • \\
\hline Tomato (cherry) & Solanaceae & 7 & 9 & $6.5 \pm 1.0$ & $98.7 \pm 22.1$ & & • \\
\hline Tomato (heritage) & Solanaceae & 5 & 6 & $2.7 \pm 0.4$ & $21.7 \pm 5.0$ & & • \\
\hline Young beetroot & Chenopodiaceae & 3 & 4.5 & $1.1 \pm 0.2$ & $25 \pm 5.9$ & - & - \\
\hline Young garlic & Alliaceae & 3 & 5 & $1.8 \pm 0.3$ & $30.0 \pm 6.9$ & & - \\
\hline Young turnip & Brassicaceae & 2 & 4 & $2.8 \pm 0.4$ & $21.2 \pm 4.9$ & • & \\
\hline Zucchini & Cucurbitaceae & 3 & 4.5 & $5.2 \pm 0.8$ & $25.3 \pm 5.6$ & - & • \\
\hline
\end{tabular}

In London, some urban farmers grow only high added-value leaf vegetables called "greens," indicated by (G), while others opt for a wider offer. *In the case, where the crop can be grown outdoors or in tunnels, the yields are indicated for crops grown in tunnels. Outdoors, yields are allocated a 70\% coefficient. **This workload dedicated to production does not integrate commercial tasks. The values given correspond to the running stage. In the setting up stage, the production workload was increased by $62 \%$ on average because farmers built their own equipment (Morel et al. 2017)

using the concepts of credibility (scientific adequacy), saliency (relevance to practitioners), and legitimacy (fair and unbiased information production respecting stakeholders' values and beliefs) as defined by Cash et al. (2003). Before the workshop, we created a framework of relevant themes to discuss with microfarmers, based on the modeling outputs. The main topics were validation of the model and potential use by urban farmers, interactions between marketing strategies and socio-ecological aspirations, access to resources in London (land, labor, financial support), and further research possibilities.

As a guide to stimulate wider discussion, this framework integrated the main concerns that were raised by microfarmers 
Table 4 Variables and options considered to build contrasting scenarios of London microfarms

\begin{tabular}{ll}
\hline Variable & Option \\
\hline Marketing offer & $\begin{array}{c}\text { Focusing on "greens": only short-cycle high added-value leaf } \\
\text { vegetables, salads and herbs (10 crops) were grown to maximize sales } \\
\text { per unit area. Three-year rotation in outdoor and tunnel area. } \\
\text { Wide offer of crops: } 36 \text { crops were grown to contribute significantly to } \\
\text { the diet requirements of urban people in terms of vegetables. }\end{array}$ \\
Four-year rotation outdoors and 3-year rotation in tunnels. \\
No tunnels \\
15\% of cultivated acreage grown in tunnels \\
Ratio of tunnels in cultivated acreage of cultivated acreage grown in tunnels \\
40\% of cultivated acreage grown in tunnels \\
Low-selling prices for organic vegetables in London (see Table 1) \\
High selling prices for organic vegetables in London (see Table 1) \\
Light: $20 \%$ of total workload* dedicated to commercial tasks \\
Medium: $30 \%$ of total workload dedicated to commercial tasks \\
High: $40 \%$ of total workload dedicated to commercial tasks \\
Setting up stage where workload consisted entirely of building own \\
equipment from second-hand or recycled material \\
Running stage where none of the workload consisted in building own \\
equipment \\
Low cost: labor cost of $£ 9.4 \mathrm{~h}^{-1}$ (London living wage considered as the \\
official minimal acceptable wage to live in London) and land rent \\
cost of $£ 0.25 \mathrm{~m}^{-2}$ per year \\
High cost: labor cost of $£ 15 \mathrm{~h}^{-1}$ and land rent cost of $£ 0.45$ m ${ }^{-2}$ per year \\
Stage of development
\end{tabular}

*Overall workload includes production workload dedicated to cropping activities and commercial workload during the semi-structured interviews and supported by the existing grey literature (Sustain 2012, 2016). In particular, it highlighted (i) the necessity to compare the economic performances of the different scenarios with the satisfaction they could bring as far as farmers' social and ecological aspirations were concerned and (ii) the articulation of the growing activities (modeled by MERLIN) with complementary social work activities (not modeled). We responded and adapted to questions and issues raised by participants over the course of the workshop. In the body of the text, quotes of the participants appear in italics, followed by a letter (from "A" to "J") identifying the participant in reference to Table 1.

\section{Results and discussion}

\subsection{Modeling outputs of the different scenarios on economic viability}

The likelihood of viability was higher in the running stage (65 $\pm 33 \%$; \pm stands for standard deviation throughout the paper) than in the setting up stage $(29 \pm 31 \%)$ and in the low-cost hypothesis $(64 \pm 32 \%)$ than in the high-cost hypothesis $(28 \pm 30 \%)$. This showed that setting up a microfarm could be challenging because of the extra work required for the farmer to build his/her own equipment and highlighted the strong impact of the cost of land and labor on viability (Fig. 2).

Focusing on high added-value greens increased the likelihood of viability $(59 \pm 36 \%)$ compared to selling a wide range of crops $(34 \pm 34 \%)$. Likewise, high selling prices increased the likelihood of viability $(67 \pm 34 \%)$ compared to low prices $(27 \pm 29 \%)$. The likelihood of viability increased with the proportion of tunnels per cultivated acre and decreased with the level of commercial workload, as illustrated in Fig. 3. In average, the highest ratio of tunnels (0.4) led to $51 \pm 37 \%$ viable simulations, whereas the likelihood of viability was $42 \pm 37 \%$ with no tunnels (0). Light commercial workloads led to $56 \pm 36 \%$ of viable simulations, whereas heavy commercial workloads led to $37 \pm$ $35 \%$ of viable simulations.

For an annual workload of $1800 \mathrm{~h}$, the average utilized agricultural area (UAA) of viable simulations was $2924 \pm$ $910 \mathrm{~m}^{2}$. High selling prices made it possible to reach viability on a smaller UAA $\left(2782 \pm 884 \mathrm{~m}^{2}\right)$ than did low selling prices $\left(3251 \pm 887 \mathrm{~m}^{2}\right)$.

For the high-cost hypothesis, the average UAA was higher $\left(3233 \pm 884 \mathrm{~m}^{2}\right)$ than for the low-cost hypothesis $(2787 \pm$ $886 \mathrm{~m}^{2}$ ). This showed that the most constraining economic options (low selling prices and high costs) required a larger 
Fig. 2 Viability ratio of the simulations according to marketing offer, prices, and development stage for the lowcost hypothesis (a) and the highcost hypothesis (b). Scenarios are viable when the viability ratio is under 1 (green zone). Focusing on high added-value greens and high prices increased the likelihood of viability. The setting up stage and the high-cost hypothesis decreased the likelihood of viability

\section{Viability ratio}
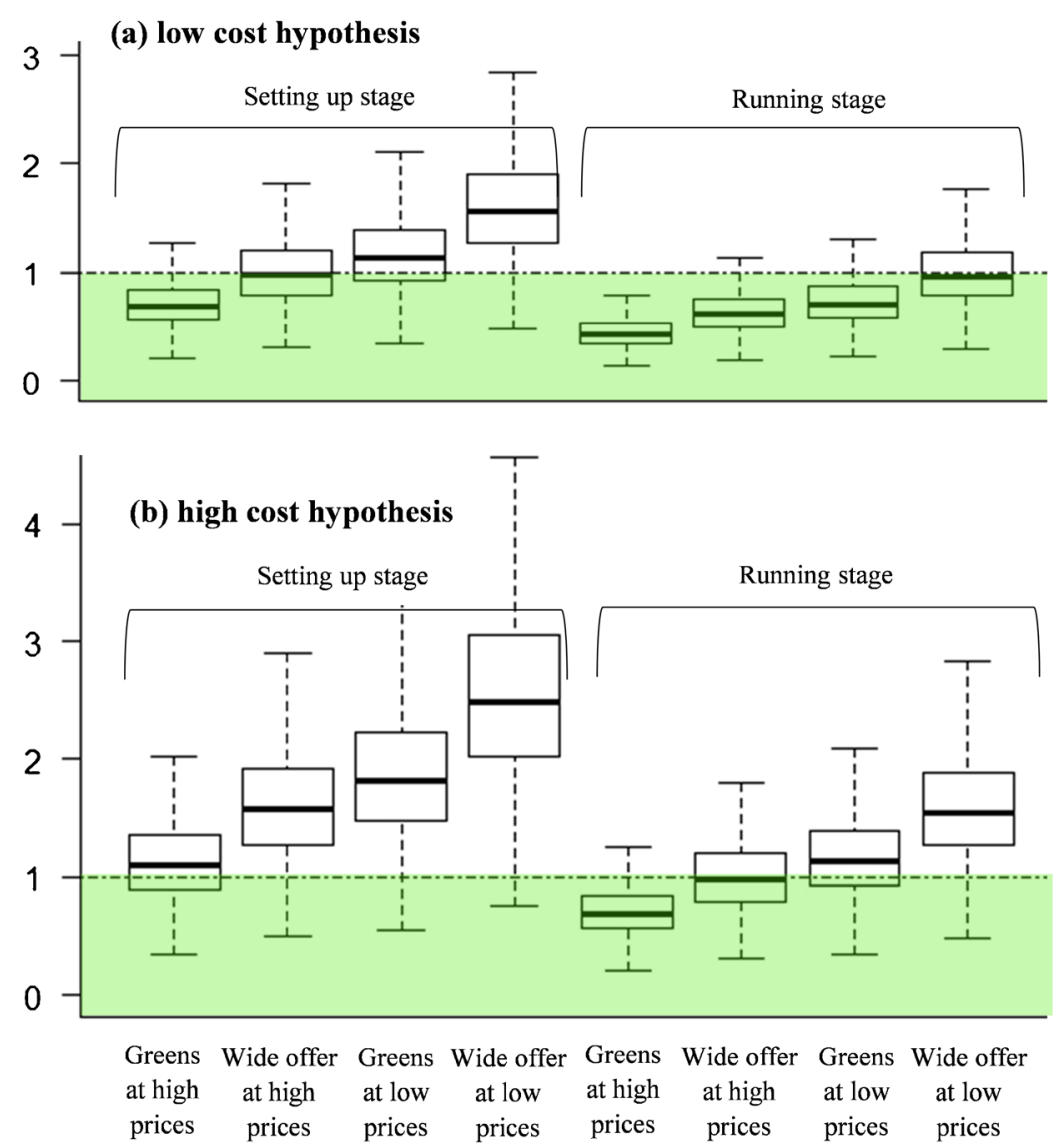

Combination of marketing offer and pricing strategy area, to be able to reach viability. The average UAA of viable simulations ranged from $3254 \pm 979 \mathrm{~m}^{2}$ with no tunnels to $2683 \pm 815 \mathrm{~m}^{2}$ for $40 \%$ of tunnels. A higher ratio of tunnels decreased the UAA of viable simulations because tunnels allowed for shorter cropping cycles (more crops per year) and more winter crops.

\subsection{Urban farmers discuss marketing strategies}

The modeling outputs highlighted the fact that the most profitable marketing strategy was to focus on the production of high added-value greens sold at a high price. According to participants, this meant selling mainly to restaurants. However, selling to restaurants was perceived as increasing the commercial workload, which decreased the likelihood of economic viability (Fig. 3). As most restaurants did not buy big quantities, this resulted in a higher number of delivery points. Delivery was, however, a major challenge in London because of the traffic. Most chefs were considered to be particularly demanding about the produce they wanted to buy: "they always change their mind and ask for really specific and fancy stuff" (D). Vegetable box schemes or farmers' markets, requiring a wider offer of crops, released these constraints because they relied on a limited number of delivery points and customers were less demanding: "It's better when people take what you have" (D). For most participants, selling to restaurants was perceived as contradictory to their strong commitment to change the food systems, because "You're not feeding real people with a few mixed leaves and herbs in the corner of a plate" (B). Moreover, high selling prices were seen as limiting the access of all urban citizens to local and healthy food, which was often a priority for urban farmers.

Despite the ethical and practical limits of selling to restaurants, most participants sold part or all of their produce through this channel, which could be considered as a tradeoff between their economic and social aspirations (Morel and Léger 2016). This trade-off was perceived differently by the participants: (i) either as a temporary trade-off during the setting-up stage where the likelihood of economic viability was the lowest (Fig. 1) - "Setting up is hard in any business" (C) - considering that the marketing offer could be widened in the running stage, or (ii) as a way to create an internal subsidy mechanism, a so-called Robin Hood strategy (E) which consisted in selling part of the harvest "at higher prices to richer people" in order to sell another part of the harvest "at 


\section{Viability ratio}
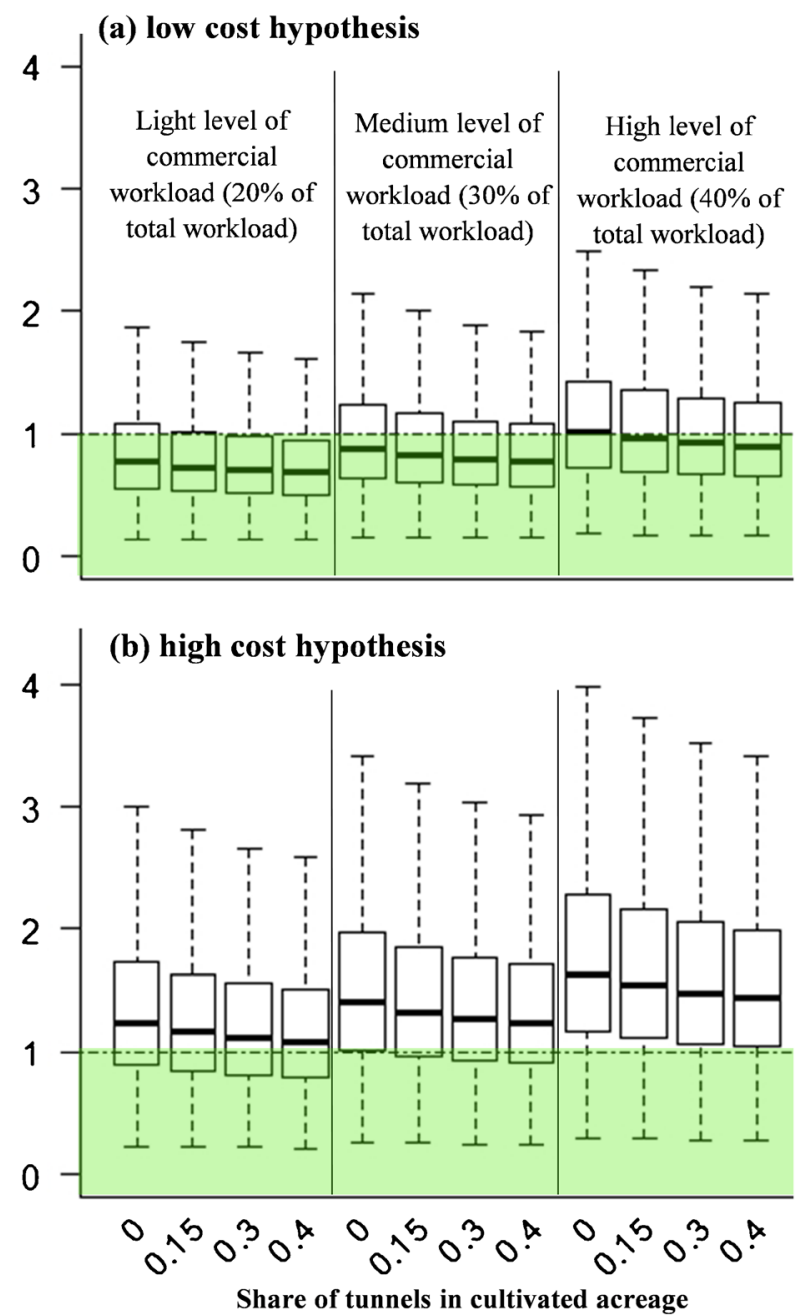

Fig. 3 Viability ratio of the simulations according to the ratio of tunnels and the level of commercial workload for the low-cost hypothesis (a) and the high-cost hypothesis (b). Scenarios are viable when the viability ratio is under 1 (green zone). A bigger proportion of tunnels increased the likelihood of viability. A heavier workload dedicated to commercial activities and the high-cost hypothesis decreased the likelihood of viability

lower prices to poorer people." In addition to these economic and social considerations, producing only greens raised ecological questions in terms of cultivated biodiversity. Even if rotation criteria were respected, the lower number of botanical families in this strategy (Table 2) was perceived as a threat to the long-term ecological sustainability of their organic farming systems.

Some microfarmers, nevertheless, had more positive views about selling to restaurants under certain conditions. For example, selling fresh produce to a single café or one situated close to the microfarm limited delivery logistic problems and fostered trusted relationships with chefs ready to commit to cooking dishes with ingredients available in-season from the farm (Inwood et al. 2008; Taylor 2009).

\subsection{Urban farmers discuss access to resources and labor remuneration}

All participants agreed that accessing land in cities was a major challenge of urban farming. This is consistent with the existing literature (Kaufman and Bailkey 2000). They noted that the high-cost hypothesis chosen for land rent in the model, $£ 0.45 \mathrm{~m}^{-2}$ per year, was relevant only to Outer London. In Inner London, this cost could rise to $£ 2.5 \mathrm{~m}^{-2}$ per year or more. Considering this rent cost in simulations would sharply decrease the likelihood of microfarms' viability, which explained why most microfarms were located in Outer London. No microfarmers owned their land, and in general, the lease was rather short, which was one of the barriers to microfarms developing more strategic longer-term planning and attracting further resources and investment. To keep a rent cost within the range considered in the model, participants highlighted the importance of making agreements with local councils. In some cases, local councils even allowed microfarmers to access a plot for a symbolic cost of a "peppercorn rent" ( $£ 1$ a year for example). In exchange for accessing land for free, or at a lower rate, microfarmers had to bring benefits to the community through a diversity of social activities such as training unemployed people, teaching children about nature and food, organizing community events, and building community cohesion through gardening. These activities were in line with the microfarmers' social aspirations but were a necessary condition for accessing land as "councils would not rent the land without social activities" (I).

The strong networks created within local communities through a variety of social activities, and the growing desire of urban people to reconnect to nature allowed microfarmers to access free labor through volunteer work. Free labor was not considered in the model and was perceived as a lever to raise the likelihood of viability of urban farms. Social work also allowed microfarmers to raise funds through charitable grants, private donations, and community crowd funding. The role that social work played in microfarmers' economic viability varied among participants: (i) Social work was central and not separated from food production-"Our model is based on providing social service" (J); or (ii) social work was important to support the integration of the farm in the local community, but food production was the basis of other activities and had to be economically viable as such. In the first case, funds raised to support the social work could be transferred to cover part of the costs of food production. In the second, the pressure of economic viability was higher as the funds raised were dedicated to social work only. All participants had been given funds to invest in second-hand equipment and facilities (e.g. tools, tunnels, building, etc.). This matched the hypothesis of the model that precluded bank loans and equipment depreciation. Without this support from the public sector and/or civil society, microfarmers would 
have had difficulties in making any investments, as banks were reluctant to finance their projects because "horticulture is too risky, especially in cities" (C).

Although social work was crucial in the economic viability of microfarms, participants stressed that they often felt overwhelmed by the complexity of managing a "hurricane of two components: social work and food production" (D). Even if volunteer labor was a source of free "working time" (D), it was perceived to require extra energy and time to "constantly train volunteers" (D) whose turnover on the farm was high and whose knowledge and farming skills were low. This tension between food production on the one hand and commitment to social activities on the other has been highlighted by Ferguson (2015).

The options for labor remuneration in the model corresponded to participants' expectations in terms of personal income. Most of them considered it more reasonable to target the London living wage $\left(£ 9.4 \mathrm{~h}^{-1}\right)$, given the difficulty of creating sufficient added value to pay higher wages, as illustrated in Figs. 2 and 3. Only one participant targeted an income of $£ 15 \mathrm{~h}^{-1}$, focusing on greens sold at a high price. The London living wage was the minimum estimated to cover the basic cost of living in London. Despite most microfarmers having higher education and an ability to earn higher income, they accepted this minimum wage in order to be coherent with their socio-ecological aspirations. Most participants argued that being a microfarmer went with a low-cost "lifestyle choice" (A), involving on-farm consumption to limit buying food, cycling rather than taking the expensive underground (subway), sharing a flat with roommates or living on a boat, and relying on family support. Only two participants were full-time microfarmers. The rest worked part-time on the farm and received complementary incomes from extra-farm activities corresponding to regular pluri-activity strategies (Fuller 1990).

\subsection{Validation of the modeling outputs, limits, and methodological perspectives}

The model was deemed to be credible because the order of magnitude and the respective increase or decrease in the likelihood of economic viability in the contrasting scenarios were in line with practitioners' expertise and personal experience. It was perceived as salient because the strategic choices that microfarmers considered as key for microfarms' economic viability were represented by the different variables. This modeling exploration was seen as legitimate because microfarmers had a strong interest in the model developed in France. The model's legitimacy seemed to increase as it was not prescriptive. It presented a global picture of the economic viability of contrasted scenarios as a thinking basis to be discussed, rather than producing quantitative references for an optimal scenario. It was in line with the expectations of urban farmers, who argued that they faced a complex reality of which many dimensions would be hard to model: "It is impossible to put community into equations" (J).

The study has various limits. The MERLIN model does not allow one to simulate contrasting climatic scenarios which may impact yields, periods of sales, and prices. Further research could be implemented to better integrate climatic factors and extreme events in MERLIN, which could allow us to simulate and discuss climatic scenarios with urban farmers in order to support them in the design of diversified farming systems resilient to climate change. This exploratory study investigated a variety of themes around microfarms and linked them together, but the analysis of each theme could be deepened. For example, the challenge of managing the complexity related to combining food production and social work, or of choosing commercial strategies depending on social aspirations and the context would deserve specific studies on their own.

In the simulations, viability was analyzed based on added value per unit area and per hour of labor (Eq. 2). The impact of farm size was not modeled, although the cultivated area of the largest farm in the study was more than 100 times greater than that of the smallest (Table 1). Size can impact farmers' concerns, strategies, and viability (van der Ploeg et al. 2009). This issue was not raised spontaneously by urban farmers during the workshop but will require further investigation in the case of urban farms.

We assessed the economic viability on the basis of hypotheses about the market and the socio-political context drawn from the current situation observed in London (levels of prices, relative low cost of land allowed by a partnership with local institutions, initial investment funded by charities or donations). Investigating more deeply the impact of marketing and socio-political context on the viability of urban microfarms would be necessary as this context could change favorably or unfavorably under the influence of various factors (e.g. changes in the societal recognition of urban agriculture, competition on land, the economic context, policy-making, etc.).

Despite the significant errors associated with estimates and the variability of modeling outputs, our modeling approach was a useful tool to stimulate wider discussions and build knowledge. The main challenge for further modeling urban farms would be to determine what makes sense for stakeholders and is realistic to model quantitatively, and what should be left to qualitative discussions. To enhance the predictive power of the model in London, microfarmers pointed out that they could collect their own data on yields, workload, and vegetable cropping cycles' possibilities, instead of using the model parameterized in France. However, enhancing the predictive power of the model was not a priority for urban farmers. According to them, collecting and discussing their own data collectively would help (i) to raise awareness among 
idealistic microfarmers about the "pragmatic" challenges they would face (E); (ii) to improve microfarmers' reflexivity and strategic choices on farming practices, marketing, and technical efficiency; and (iii) to create a learning culture (Voinov and Bousquet 2010) among networks of microfarmers. When we carried out the research, some urban farmers were not able to tell if some crops were more profitable than others or required more time than others. Such observations echoed our own experience working in France with microfarmers. Some of them were at times really surprised to see that measurements of yields and workloads, or precise calculations of margins crop by crop on their farm were in contradiction with what they had initially imagined or thought. Those farmers acknowledged that collecting their own measurements and field observations and exchanging them with other practitioners could support their decision making, as demonstrated by Roling and Wagemakers (2000). The appropriate role of researchers in such learning processes will be discussed in the conclusion.

\subsection{Main highlights of this study}

The existing literature about the economic viability of urban farms in industrialized countries is limited and mainly focused on the USA (Kaufman and Bailkey 2000). Our study has shown that urban microfarms could be economically viable in a big European city such as London. Various levers have been highlighted to enhance the viability of urban farms through modeling and discussions with stakeholders: (i) focusing on short-cycle and high added-value leaf vegetables called "greens," (ii) selling at high prices to restaurants, (iii) using tunnels, (iv) guaranteeing a low cost of land rent and funding initial investment through a partnership with local councils or charities, (v) employing volunteer labor, and (vi) accepting low remuneration in exchange of the satisfaction that urban farming can bring in terms of socioecological aspirations to be part of making cities more sustainable. Some of these levers had already been suggested in the literature, such as niche markets or using volunteer labor (Kaufman and Bailkey 2000). The novelty of this study is that it models quantitatively and discusses their impact on viability with urban farmers. The relative share of greens grown by urban farmers and marketed at high prices was a trade-off for urban farmers because it conflicted with their socioecological aspirations of producing a wide biodiversity of crops for average-income and poor urban citizens. The ability of urban farmers to access community resources (volunteer labor, access to land, and investment funds) depended on their commitment in social work activities. Social work seemed to be a key in the viability of urban farms but increased the complexity of farm management. Finding a balance between agricultural production and social work is a major challenge of urban farming.

\section{Conclusion}

Although this study has highlighted the fact that urban microfarms could be viable, they are still a drop in the ocean in terms of how much food is produced and consumed in London (Litherland 2014). If microfarms are to play a role in the transformation of food systems in cities, engagement with the wider political context cannot be ignored. In the current exploratory form, we do not think that our model could be used by funders or policy makers to evaluate the likely success of urban farm projects. Urban farmers pointed out in the workshop that success relied on far more factors than the few variables considered by MERLIN. However, urban farmers raised the idea that the modeling outputs could serve as a communication tool to make policy makers and funders aware of the challenges of urban farming. They valued the variability of these outputs, even though the latter can at first glance be interpreted as a lack of precision or low predictive power of the model. According to the farmers, it was a perfect illustration that urban farming is highly uncertain and risky, which could convince policy makers and funders of the need for urban agriculture to be supported if it is to be developed. The fact that the model emphasizes the impact of land rent and labor costs on economic success may help urban farmers to convince policy makers of the need for greater enabling conditions in land access and for support for the social activities of urban farms because they can be a source of volunteer labor. Nevertheless, enabling land access is not only about costs. Agreements and leases ensuring long-term land use security are required, while today most microfarmers grow food on plots rented with short-term and precarious leases. Given the strong social and ecological agenda of urban farms, other indicators of wider sustainability should be integrated into the model to make it more suitable to planning or assessing urban farming projects. Inclusion and valuation of unproductive ecosystem services could show that projects with the most positive societal impacts may not be the most profitable ones. Such tensions were already raised in the study where focusing on green high added-value crops sold to restaurants (most profitable option) had a lower social impact and raised more ecological issues (limited rotation) than producing a wide range of crops sold at lower prices to "really feed people." Integrating wider sustainability indicators would probably bring to light the fact that urban planners, like urban farmers, have to find trade-offs between the economic, social, and ecological impacts of urban agriculture.

In this study, we decided to adapt the existing MERLIN model to London and to limit the involvement of farmers. The idea was to explore the extent to which we could convince initially rather reluctant urban farmers of the relevance of developing more ambitious participatory research in the future. We have to confess that our underlying assumption was that farmers were not willing to "waste" their precious time in 
participatory workshops and focus groups, and that offering a practical simulation model could be a motivation for them to become more involved. The workshop that we organized showed that we were partially wrong. Although it is true that urban farmers appreciated the simulation approach, further developing the model to transform it into a reliable decisionmaking tool was not perceived as a priority. On the contrary, farmers seemed keen to get further implicated in research projects which create a specific space they could use to collectively discuss and share their experience. They mentioned that collecting data in London could be a priority but above all in order to feed a collective reflexive and learning process and not to develop a "magic decision-making tool." To take this path, it appears that the right role of scientists may not be to drive the research, as we did in this exploratory study (even if this research involved participatory aspects), but to facilitate a more radical participatory approach, where farmers identify research needs, help to design the research, and provide regular feedback to make it evolve in the most relevant direction. To support such a long-term and ambitious process, urban farming studies probably have much to learn about participatory research with smallholders in the global South or with more conventional farmers in the North.

Acknowledgements We thank urban farmers in London who dedicated time to this research and the Ile-de-France Region which funded part of the project.

\section{References}

Ackerman K, Conard M, Culligan P et al (2014) Sustainable food systems for future cities: the potential of urban agriculture. Econ Soc Rev 45: 189-206

Barthel S, Parker J, Ernstson H (2015) Food and green space in cities: a resilience lens on gardens and urban environmental movements. Urban Stud 52(7):1321-1338. https://doi.org/10.1177/ 0042098012472744

Bezner Kerr R, Snapp S, Marko C et al (2007) Participatory research on legume diversification with malawian smallholder farmers for improved human nutrition and soil fertility. Exp Agric 43(04):437453. https://doi.org/10.1017/S0014479707005339

Biel R (2014) Visioning a sustainable energy future: the case of urban food-growing. Theory Cult Soc:1-20

Cash DW, Clark WC, Alcock F, Dickson NM, Eckley N, Guston DH, Jäger J, Mitchell RB (2003) Knowledge systems for sustainable development. Proc Natl Acad Sci 100(14):8086-8091. https://doi. org/10.1073/pnas.1231332100

Chang M, Morel K (2017) Dataset of cropping cycles possibilities considered by the MERLIN model for urban microfarms in the London context [Data set]. Zenodo. https://doi.org/10.5281/zenodo.1010224

CFGN, Community Food Growers Network (2016) Manifesto. https:// www.cfgn.org.uk/manifesto. Accessed 31 Aug 2016

Colasanti K, Hamm MW (2010) Assessing the local food supply capacity of Detroit, Michigan

Connors P, McDonald P (2011) Transitioning communities: community, participation and the transition town movement. Community Dev $\mathrm{J}$ 46(4):558-572. https://doi.org/10.1093/cdj/bsq014
Daniel AC (2017) Fonctionnement et durabilité des microfermes urbaines, une observation participative sur le cas des fermes franciliennes. Chaire Eco-conception, AgroParisTech, INRA, UMR SADAPT, France

Eisenhardt KM (1989) Building theories from case study research. Acad Manag Rev 14:532-550

Ferguson J (2015) Permaculture as farming practice and international grassroots network: a multidisciplinary study. Dissertation, University of Illinois. https://www.ideals.illinois.edu/bitstream/ handle/2142/89037/FERGUSON-DISSERTATION-2015.pdf? sequence $=1$. Accessed 20 June 2016

Fuller AM (1990) From part-time farming to pluriactivity: a decade of change in Rural Europe. J Rural Stud 6(4):361-373. https://doi.org/ 10.1016/0743-0167(90)90049-E

Garnett T (2000) Urban agriculture in London: rethinking our food economy. Grow Cities Grow Food Ger Found Int Dev Feldafing Ger 477-500

Glaser BG, Strauss AL (2009) The discovery of grounded theory: Strategies for qualitative research. Transaction Publishers

Inwood SM, Sharp JS, Moore RH, Stinner DH (2008) Restaurants, chefs and local foods: insights drawn from application of a diffusion of innovation framework. Agric Hum Values 26(3):177-191. https:// doi.org/10.1007/s10460-008-9165-6

Just Space (2016) Towards a community-led London plan: policy directions and proposals. https://justspacelondon.files.wordpress.com/ 2013/09/just-space-a4-community-led-london-plan.pdf. Accessed 10 Sept 2016

Kaufman J, Bailkey M (2000) Farming inside cities: Entrepreneurial urban agriculture in the United States. http://www.urbantilth.org/wpcontent/uploads/2008/10/farminginsidecities.pdf. Accessed 24 Aug 2016

LDA, London Development Agency (2006) The Mayor's London food strategy. https://www.london.gov.uk/sites/default/files/the_mayors food_strategy_2006.pdf. Accessed 24 Aug 2016

Litherland R (2014) An open letter to the co-operative. Seedlings from the smoke - musings of an urban market gardener. Organiclea, London

Lovell ST (2010) Multifunctional urban agriculture for sustainable land use planning in the United States. Sustainability 2(8):2499-2522. https://doi.org/10.3390/su2082499

Martin G, Theau J-P, Therond O, Martin-Clouaire R, Duru M (2011) Diagnosis and simulation: a suitable combination to support farming systems design. Crop Pasture Sci 62(4):328-336. https://doi.org/10. 1071/CP10361

McClintock N, Cooper J, Khandeshi S (2013) Assessing the potential contribution of vacant land to urban vegetable production and consumption in Oakland, California. Landsc Urban Plan 111:46-58. https://doi.org/10.1016/j.landurbplan.2012.12.009

Miles MB, Huberman AM (1984) Qualitative data analysis: a sourcebook of new methods. SAGE Publications Inc, Beverly Hills

Morel K (2016) Small can be beautiful for organic market gardeners: a "grounded" modelling exploration of the viability of French microfarms, pp. 143-174, in Morel, Kevin, 2016. Viabilité des microfermes maraîchères biologique. Une étude inductive combinant méthodes qualitatives et modélisation. Dissertation. University Paris-Saclay. https://hal.archives-ouvertes.fr/tel01557495/document. Accessed 14 Oct 2017

Morel K, Léger F (2016) A conceptual framework for alternative farmers' strategic choices: the case of French organic market gardening microfarms. Agroecol Sustain Food Syst 40(5):466-492. https:// doi.org/10.1080/21683565.2016.1140695

Morel K, San Cristobal M, Léger FG (2017) Small can be beautiful for organic market gardens: an exploration of the economic viability of French microfarms using MERLIN. Agric Syst 158:39-49. https:// doi.org/10.1016/j.agsy.2017.08.008 
Morel K, San Cristobal M, Léger FG (2018) Simulating incomes of radical organic farms with MERLIN: a grounded modeling approach for French microfarms. Agric Syst

Olivier de Sardan J-P (2008) La rigueur du qualitatif: les contraintes empiriques de l'interprétation socio-anthropologique. AcademiaBruylant, Louvain-La-Neuve

Pearson LJ, Pearson L, Pearson CJ (2010) Sustainable urban agriculture: stocktake and opportunities. Int J Agric Sustain 8(1):7-19. https:// doi.org/10.3763/ijas.2009.0468

Pretty JN (1995) Participatory learning for sustainable agriculture. World Dev 23(8):1247-1263. https://doi.org/10.1016/0305-750X(95) 00046-F

Roling NG, Wagemakers MAE (2000) Facilitating sustainable agriculture: participatory learning and adaptive management in times of environmental uncertainty. Cambridge University Press

Sustain, the alliance for better food and farming (2012) A growing trade - a guide for community groups growing food to sell in our towns and cities. http://www.sustainweb.org/publications/a_ growing trade/. Accessed 10 May 2016

Sustain, the alliance for better food and farming (2016) Growing enterprise guide, updated April 2016. http://www.sustainweb.org/ publications/growing enterprise guide/. Accessed 10 May 2016

Taylor AK (2009) Sustainable cities and local food systems: a partnership between restaurants and farms in Portland, Oregon. Disseration. University of Stellenbosch

Troitzsch KG (2004) Validating simulation models. In: Proceedings of the 18th European Simulation Multiconference. SCS, Erlagen, p 98-106

van der Ploeg JD, Laurent C, Blondeau F, Bonnafous P (2009) Farm diversity, classification schemes and multifunctionality. J Environ Manag 90(Supplement 2):S124-S131. https://doi.org/10.1016/j. jenvman.2008.11.022

Voinov A, Bousquet F (2010) Modelling with stakeholders. Environ Model Softw 25(11):1268-1281. https://doi.org/10.1016/j.envsoft. 2010.03.007 